\title{
Central Fatness among Secondary School Adolescents in Ibadan, Nigeria \\ DOI: 10.36108/NJSA/6102/14(0210)
}

\author{
Comfort R. Oyom \\ Mofeyisara O. Omobowale* \\ Adebola E. Orimadegun \\ Adesola O. Olumide \\ Olukemi K. Amodu \\ Institute of Child Health \\ College of Medicine, \\ University of Ibadan \\ Ibadan, Nigeria
}

*Corresponding Author: amkemi@hotmail.com

\begin{abstract}
One of the most pressing health problems facing public health in the world today is the astronomically increasing over weight and obesity cases among children and adolescents and Nigeria is not an exception to this problem. The increase in weight and obesity in reality cannot be separated from socio-cultural issues, simply because it cuts across all gender and classes. This study therefore, examined the context (reality in line with existing medical, social and cultural values) of central fatness among secondary school adolescents in Ibadan, Nigeria. The data for the study was collected through structured questionnaires and an assessment of anthropometric measurement. The study reveal increasing over weight and obesity cases among secondary students in, Ibadan, and social construction acceptance of obesity as a symbol of good living plays a major role in the prevalence. Hence, it is as a matter of urgency that there should be a strong awareness on the dangers associated with increasing accumulation of excess fat among secondary adolescents in Ibadan.
\end{abstract}

Keyword: central -fatness, obesity, adolescent, context, socio-cultural

\section{Introduction}

Central fatness simply refers to abdominal obesity. It describes fat accumulation in the upper part of the body which when in excess can be of negative impact on the general body health. "Fat was more fashionable in the West far into the nineteenth century; however, between 1950-1960, slender became le derniet cri" (Wedwick, 1998: 29). Wedwick's assertion above somewhat also describes the values attached to "fat" in colonial and postcolonial Nigeria. In the last two decades, one of the most pressing health problems in the world is the increasing over-weight and obesity cases among children and adolescents (Ali, Amialchuk and Renna, 2011; Ostojic, 2011; Stojanovic, Stojanovic, Maric and Njaradi and McCarthy, Elilis and Cole, 2003). Ostojic et al. (2011) report that one out of every four children in both less developed and more developed societies are overweight or at the risk of 
obesity. World Health Organization (2012) reports that obesity has reached epidemic proportions globally, with at least 2.8 million people dying each year as a result of being overweight or obese. Once reported as the problem of highincome countries, obesity is now also prevalent in low- and middle-income countries (WHO, 2012). The prevalence of obesity has increased sharply over the last three decades; with about $65 \%$ of adults classified as overweight or obese (Icks, Moebus, Feuersenger, Haastert, Jockel and Mielck, 2007 and Quelly and Lieberman, 2011). The prevalence of obesity has risen even more sharply among adolescents and young adults, with many experiencing obesity into adulthood (Hedley et al., 2004, Magarey, Daniels, Boulton and Cockington, 2003). Obesity also has high economic implications with about US $\$ 100$ billion spent yearly on obesity-related health care (Wolf and Colditz, 1998; Moffat, 2010).

The reported prevalence of overweight and obesity among adolescents cuts across gender and classes in diverse cultural spaces, because there are different social and cultural factors responsible for the prevalence. For instance, lack of physical activities and physical fitness has been identified as one factor that may account for high overweight and obesity prevalence among the adolescents in the contemporary time (Ostojic et al., 2011; Sudha, Paul and Diane 2013). In addition, societal beliefs and values have also been included as contributory factors to risk of fatness among children and adolescents. Upton (2010), showed how fatness (fat egg concept) in females is positively associated with culture of fertility in Botswana. Likewise, Popenoe (2003) from her ethnographic report gives vivid accounts of Azawagh Arabs' (or Moors) "practice of fattening girls in relations to what they culturally defined as beauty and desirable" (Popenoe, 2003: 589). On the contrary, obesity has been found to be a risk factor of non-communicable diseases such as cancer, cardiovascular disorder, diabetes and renal disease among other health challenges (Ali, Amialchuk and Renna, 2011; Popenoe, 2003). Furthermore, Yiting, Eric, Alpa, Carmen, Marjorie, Michael and Eugenia (2008) in their study of the relationship between increased waist circumference, Body Mass Index (BMI) and colorectal cancer, confirmed that "waist circumference is associated with increased colorectal cancer incidence, possibly partially independent of BMI" (Yiting et al., 2008: 783), both in men and women. Likewise, studies also associate waist circumference with identification of cardiovascular risk factor, therefore, increase in Waist circumference (WC) is a predictor for increasing health risk (Han, Leer, Seidell, Lean, 1995; Okoh and Okoh, 2013).

In Nigeria, initial data in the middle and later part of the $20^{\text {th }}$ century suggest a low prevalence of overweight and obesity (Johnson, 1970; Lawoyin Asuzu and Karfman, 2002). However recent reports from various studies indicate an increasing prevalence (Cooper, Rotimi and Ataman, 1997; Akpa and Metol, 2006; and Quelly and Lieberman, 2011). Some studies in Nigeria have shown figures similar to the situation in the developed world indicating obesity prevalence rates of $71.6 \%$ in females and $50.55 \%$ in males among 
hypertensive patients in Nigeria (Amodu, Mba and Lawson, 2005). An earlier study by Kadiri and Salako (1997) revealed that obesity was present in $21 \%$ males and $28 \%$ females while in a group of Type 2 diabetics $83 \%$ were overweight or obese, all suggesting marked increase in prevalence comparable to what is obtained in the developed countries.

Following the submissions so far, it is important to note that in spite of medical findings and interpretations, socio-cultural perceptions and understanding provide foundational underpinning for the acceptance and/or rejection of fatness across cultures (Ali, Amialchuk and Renna, 2011). Attention has often been directed at fatness as health challenge, in terms of beauty and also as a reflection of class relative to socio-cultural group (Ali, Amialchuk and Renna, 2011). Aside the groups that have often been popularly studied, it is noteworthy to state that across cultures, adolescents are increasingly assuming obese postures even in developing countries (Ali, Amialchuk and Renna, 2011).

Adolescence is a critical transitional social, cultural, medical, and psychological phase of life, during which significant changes in the body and social compositions occur (Buffa, Floris, Marini and Ortu, 2003). These changes especially in the body tend towards accumulation of excess fat, which may in the socio-cultural context translate to a seemingly rite of passage into a new social group (Popenoe, 2003). Previous studies on adolescents in Nigeria through the employment of Body Mass Index (BMI), have shown that there is an increasing incidence of overweight among children of all ages in the country (Ben-Bassey, Oduwole and Ogundipe, 2007; Akinpelu, Oyewole and Oritogun, 2008). This simply implies that the Nigerian society is not exempted from the global health problem of overweight and obesity. This study therefore, draws on the strength of previous studies to examine the central fatness of secondary school student adolescents in Ibadan, Nigeria.

Ibadan is the capital of Oyo state and is one of the largest cities in Africa; it is one of the commercial nerve centers of Southwestern Nigeria, with numerous indigenous and modern fast food outlets also strategically located to attend to the fast moving life style of the city dwellers (Olutayo and Akanle, 2009). In their study, Olutayo and Akanle (2009) have associated the increasing number of fast food outlets in Ibadan with the increasing prevalence in obesity and other associated health challenges in the city. Adolescents are very important in the fast moving life style of the city and little attention has been given to the study of adolescents in the city of Ibadan in relations to obesity. This study hence, examined the context (reality in line with existing medical, social and cultural values) of central fatness among secondary school adolescents in Ibadan. 


\section{Materials and Methods}

The study adopted cross-sectional and analytical study design. Data were collected quantitatively. The major primary source of data collection was done through administration of structured questionnaires. The study population was drawn from both Public and private secondary school adolescents in junior and senior classes, aged 10 to 19 years in Ibadan North Local Government Area between 2010 and 2011. A total number of 623 adolescents were selected through the use of simple random sampling method. Instruments for measurements, a pretested, structured interviewer-administered questionnaire were used to collect data. All research assistants used for the study were trained before the commencement of the data collection process. Ethical approval was obtained from Oyo state ethical review board.

Anthropometric measurements were made with the students putting on only their school uniforms and without any shoes or socks on. Height was measured in centimetres $(\mathrm{cm})$ using a wall-mounted stadiometer. Weight was measured in kilograms $(\mathrm{kg})$ using an electronic scale. All measurements were taken twice. A third measurement was taken if the first two differed by more than $0.5 \mathrm{~cm}$ (height) or $0.3 \mathrm{~kg}$ (weight). Waist circumference was measured using a measuring tape to the nearest $0.1 \mathrm{~cm}$. Waist circumference was measured at the level of the umbilicus and the superior iliac crest. The measurement was made at the end of a normal expiration while the subject stood upright, with feet together and arms hanging freely at the sides. Waist to Height Ratio (WHtR) was calculated by dividing waist circumference by height. Means and standard deviations were calculated at yearly intervals by sex. Correlation coefficients were computed to examine the influence of age on WHtR. Waist to Height Ratio in boys and girls were compared statistically using an unpaired t-test. The proportion of adolescents with WHtR greater than 0.500 , was calculated for each age group.

\section{Findings and discussions}

\section{Socio-Demographic Characteristics}

This section provides analyses of socio-demographic data and respondents anthrometric indices. Respondents' age, sex, family type, ethnic affiliation, school type and parents' socio-economic status are discussed under socioeconomic subsection while anthropometric indices include the respondents' weight and height, weight and hip circumference, body mass index (BMI) and percentage body fat (PBF). Out of the 623 participants that were involved in this study, 60\% (374) were females while the rest (249) were males. This is an indication that a significant number of female adolescents in Ibadan have access to post-primary (secondary) education. This is an evidence of improving gender equality in access to Western education ${ }^{1}$ (Ogunjuyigbe, Ojoteitimi and

\footnotetext{
${ }^{1}$ This achievement cannot be divorced from the education history of the Western Nigeria, where European Christian Missionaries pioneered the introduction of elementary and secondary education from the late $19^{\text {th }}$ century (Aderinto, 2015), as
} 
Akinlo, 2006; Lincove, 2008), against the hitherto social preference for male education; due to improving parents and guardians consciousness about the value of female education (Tibenderana, 1985; Bolarinwa, 1987; Kirk and Garrow, 2003; Kazeem et al., 2010 and Aderinto, 2015).

Participants were adolescents aged 10 to 19 years. Overall mean age was $14.5 \pm 2.1$ years. There was no significant difference in mean age of male (14.7 \pm 2.1 years) and female (14.4 \pm 2.0 years) participants. The ages of 14 and 15 are crucial in personality development and social consciousness of adolescents. At this age adolescents, even though still under parental control are notably and increasingly gaining consciousness of their personalities, sexuality, body and "rights" (Smith, 2007; Rothbart, 2007; Ho, Cheung and Cheung, 2008). The consciousness of their body will either be negative or positive on central fatness depending on their social environment or peer pressure. Hence adolescents may either celebrate or reject central fatness (Wedwick, 1998; Buff et al., 2003).

The research further shows that the age group 14-15 years had the highest representation among male (37.8\%) and female (40.9\%) adolescents. The least represented age group was 18-19 years which comprised $7.2 \%$ of male and $4.0 \%$ of female participants. That the highest numbers of the adolescents are age 14-15 years is an indication of an increasing number of adolescents who are enlisted in school early. Ordinarily, the stipulated age of entry in Secondary school is between 10 and 12 years. By the age of 14-15 years, many are in senior secondary classes preparing to graduate from that stage of modern education. This is also quite symbolic. Early education of wards is a symbolic reality of the increasing consciousness of parents and guardians to ensure the early education of wards to avoid the financial challenges associated with retirement especially since the days of Structural Adjustment Programme (Riddell, 1992; Walker, 2000 and Meagher, 2006). Thus it seems, early education of children has become a panacea to possible economic incapability at old age, especially since the children are also culturally expected to serve as parents' social security at old age (Pestieau and Ponthiere, 2013). This explains the strong representation of ages 14 to 15 and low representation of ages $18-19$ years in the study, because by about age 16 years, many would already be graduating from secondary school.

Another factor that accounts for the highest representation of ages 14-15 is due to the nature of Nigeria society where a child does not necessarily become

well as the phenomenal contribution of the government of Western Nigeria under the Premiership of late Chief Obafemi Awolowo who pioneered the introduction of free primary education across gender and class boundaries in the late 1950s (Nolte, 2009; Adebanwi, 2010). Subsequent governments especially during democratic dispensations have maintained free education policy with appreciable emphasis on female education resulting in appreciable improvement in female literacy as captured in this study. 
"mature" and independent at age 18, but until the child possesses the "...material means and recognition to...[establish] themselves as providers for others" (Nolte, 2004: 62). So for parents, children do not have to remain in secondary schools until the age of 18 when they can be legally independent. In reality, even at age 18 and even into late 20 s, many children still remain under their parents "supervision' and "material support" until they are economically viable. So the earlier parents sent them to school and provided them with the necessary wherewithal to be molded into economic "viability", the better. The essence of this explanation is that even parents desire "fatness" with maturity in their wards.

The data further reveal that $78 \%$ of the participants were from monogamous family background, followed by polygamy of $17 \%$ and $5 \%$ have single parenthood background (see Table 1 Below). The high percentage of monogamous family background among the participants is an indication that due to upward social mobility to (educated) middle class, many families have accepted modern value of "responsible" parenthood as one wife- one husband, especially among the Yoruba of Southwestern Nigeria, where polygyny used to be prestigious (Oni, 1999). This value of monogamy apart from certain religious expectations, is not independent of the contemporary hard economic realities in the country, that has over the year's handicaped many "responsible" men from expanding their family sizes and marital tentacles beyond monogamy, though many may still have extra marital affairs but with no marriage commitment (Gage-Brandon, 1992; Aderinto, 2015).

Table 1: Socio-demographic Characteristics of Participants (Family Type)

\begin{tabular}{lrrr}
\hline Characteristics & Male (\%) & Female (\%) & Total (\%) \\
\hline Family Type & & & \\
Monogamous & $205(82.3)$ & $281(75.1)$ & $486(78)$ \\
Polygamous & $33(13.3)$ & $73(19.5)$ & $106(17)$ \\
Single Parent & $11(4.4)$ & $20(5.3)$ & $31(5)$ \\
Total & $\mathbf{2 4 9 ( 1 0 0 )}$ & $\mathbf{3 7 4}(\mathbf{1 0 0})$ & $\mathbf{6 2 3 ( 1 0 0 )}$ \\
\hline
\end{tabular}

Parents' economic class revealed that $51.7 \%$ of the participants' parents were middle income earners, followed by $28.7 \%$ who were high income earners and $19.6 \%$ from the low income circle (see table 2 below). The relatively high distribution of middle income earners, is an indication that they may have extra funds to expend of ostentatious lifestyle and fatty food Many of the participants (pupils) due to their parents' socio-economic background will likely have access to attractive daily stipends with which they purchase all sorts of pastries (considered as "enjoyment") as midday refreshments at school. The observation among secondary school students in Ibadan North Local

\footnotetext{
${ }^{2}$ It is a common belief that children from monogamous family background have access to better care, well fed from the parents and many of their needs are met, unlike children from polygamous homes that are poorly feed and not really cared for.
} 
governments' areas was that many school adolescents from middle and upper income earning parents have access to daily stipends of between One Hundred Naira (approximately $\$ 0.5$ ) to One Thousand naira (\$5). These stipends are used to purchase different pastries and soft drinks, high in cholesterol from the school butteries at least five days a week. The health implication of this behaviour is not farfetched, it is reflected in the increasing reported cases of obesity and it related health challenges among adolescents in Nigeria.

Table 2: Showing Parents' socioeconomic Class

\begin{tabular}{lrrr}
\hline Characteristics & Male (\%) & Female (\%) & Total (\%) \\
\hline $\begin{array}{l}\text { Parents' socioeconomic } \\
\text { class }\end{array}$ & & & \\
Low & $42(16.9)$ & $80(21.4)$ & $122(19.6)$ \\
Middle & $140(56.2)$ & $182(48.7)$ & $322(51.7)$ \\
High & $67(26.9)$ & $112(29.9)$ & $179(28.7)$ \\
Total & $\mathbf{2 4 9 ( 1 0 0 )}$ & $\mathbf{3 7 4 ( 1 0 0 )}$ & $\mathbf{6 2 3 ( 1 0 0 )}$ \\
\hline
\end{tabular}

\section{Major Findings}

\section{Weight and Height}

This section presents and discusses the results on weight and height of the respondents. The result is discussed within the context of prevailing sociocultural values and realities of "beauty" and "attractive" body appearance in Nigeria. The overall mean weight was $47.0 \pm 9.7 \mathrm{~kg}$. In all, the female adolescents had a significantly higher mean weight $(48.0 \pm 8.9 \mathrm{~kg})$ than the male adolescents $(45.3 \pm 10.6 \mathrm{~kg})$. Female adolescents had significantly higher weight across all age groups except 18-19 years, though this difference was only significant among ages $12-13$ and $14-15(\mathrm{p}=0.000)$. At age group 18-19 years, males had significantly higher weight $18-19(\mathrm{p}=0.000)$. Furthermore, overall mean height was $157.2 \pm 9.8 \mathrm{~cm}$. There was no significant difference between the height of male $(157.9 \pm 12.4 \mathrm{~cm})$ and female $(156.7 \pm 7.6 \mathrm{~cm})$ adolescents $(\mathrm{p}$ $=0.131$ ). Females were significantly taller than males among age groups 10-11 $(\mathrm{p}=0.049)$ and $12-13(\mathrm{p}=0.027)$. Males were taller than females at age groups $16-17(\mathrm{p}=0.000)$ and $18-19(\mathrm{p}=0.001)$. Though females were slightly taller than males at age group 15-16, this difference was not statistically significant $(\mathrm{p}=0.164)$.

The data above reveal that female adolescents have bigger weight and heights than males especially between the ages of 10-11, and 12-13. Besides explanations that attribute physiological and medical reasons for females' weight and height at these age $(10-11,12-13)$ groups, it is important to note that there are cultural values associated with weight and height of adolescents. Generally, parents attribute weight and height as symbolic representations of class, beauty, status, and acceptable/good parenthood. With increasing exposure to fattening food and fast-food outlets (Olutayo and Akanle, 2009), 
many homes are growing obese children (Auld and Powell, 2009). It is also important to note, parents prefer their adolescent daughters be "big" and accumulate a "moderate bodily fat" in order to present a "beautiful" outlook (Brewis, 2010). The reason for this is not farfetched. Looking big and fat is a reflection of class and social status of the family (Ali, Amialchuk and Renna, 2011). It also socially depicts parental care and provision for the adolescent girl especially in the contemporary age of gender equality. In a way, thus, the weight (fatness) of a female adolescent also indicates fair and unbiased distribution of family resources among female and male children. Many parents will readily encourage their adolescent girls to add some weight that will symbolically put them in the "class" of the "good looking" girls in the neighbourhood, and this may account for the significant difference in male and female weight among the respondents. This also corroborates and advances the findings of Ben-Bassey, Oduwole and Ogundipe (2007), and Akinpelu, Oyewole and Oritogun (2008). Likewise, Ali, Amialchuk and Renna (2011) "the social network of weight", posit that adolescents who live in an environment of the obese will interpret obesity positively as the ideal body type. Furthermore, it is noteworthy, to state that, influenced by current trends that are advanced through the social media, and global fashion, by about age 18-19, the female adolescent prefers slim body sizes, which symbolically reflects beauty in the global trend (Wedwick, 1998). They reject obesity which is deemed as depreciative beauty. On the other hand, towards late adolescent period, there is increase in bone density among males which usually give them higher weight than females, the males accumulate weight especially in terms of broader chest and stronger bones. At this stage, the weight and height of male adolescents are socially depicted in the realms of handsomeness and muscular strength that may attract female adolescents and thus view a male suitor as an attractive and a potential "protectors", even though overweight adolescents are at the risk of a number of physical and psychological implications (Wiederman and Hurst, 1998; Rosenblum and Lewis, 1999; Fan, Dai and Wu, 2005 and Dowrkin and Wachs, 2009).

\section{Waist Circumference and Body Mass Index (BMI)}

The focus of discussion in this section is waist circumference and the Body Mass Index of respondents as interpreted from data gathered from the field. Waist circumference has been established to be a strong predictor for many illhealth related with obesity in many societies (Chen and Tunstal-Pedoe, 2005). Generally, in the study population, the waist circumference of females was higher than that of males in almost all age groups, significantly so at age groups 12-13, 14-15 and 16-17. However, for age group 18-19, males had slightly higher waist circumference. The findings reveal that girls have higher WC ratio compared to boys, except at age group 18-19. The interpretation to this significant high ratio in WC cannot be dissociated from the social and cultural value system of beauty, body and appearance as discussed above. In so far that fatness is a cultural discursive construct, which "... unravel the nexus 
of economic, cultural, and social forces that made physical appearances one of the primary contemporary indexes of individual [and communal] identity and worth" (Barbas, 2004: 1116), WC is thus a bodily expression a "preferred" status. A great majority of the respondents were from the Yoruba ethnic group. The Yoruba (has a value system where "big and fat body" is appreciated even across class boundaries (Schonfeld, 1984). Among the Yoruba, a fat or "obese" adolescent is often socially perceived as a child born with "silver spoon". This is depicted in some popular parlances used to positively describe obese children among the indigenous population; such as: $o$ n fela (the child reflects comfort and wealth), oроoтu (fat and beautiful) and ayiiluko (fat and sexy) among others. All these qualify an obese adolescent as omo t'o yin'wo (a child who bodily reflects parental care, comfort and wealth). While an adolescent with slim body, and very limited body fat and thin WC may be stigmatized even among peers and in the neighbourhood and may be referred to as "omo $t i$ ko yin 'wo" (a child who does not bodily reflect parental care). This fat body value system explains the significant increase of obesity among adolescents in Ibadan revealed in this study, because across class boundaries, parents wish their children were fat. Hence, this finding agrees with other studies that have demonstrated that overweight and obesity in Nigerian children have increased recently (Ben-Bassey, Oduwole and Ogundipe, 2007; Akinpelu, Oyewole and Oritogun, 2008). However, it can further be deduced from this conclusion that many parents and adolescent are ignorant of the danger associated with high body fat. This suggests that there is need for more awareness on the danger of fatness especially among adolescents in Ibadan.

The data also specifically shows that central or upper body fatness has increased, perhaps to a greater extent than overall fatness, such as would be indicated through changes in BMI. This agrees with other recent findings in this area (McCarthy and Ashwell, 2006). However, it could be argued that secular changes in height could account for the increases in WC over time. The WHtR, however, takes height into account, so clearly this is not the case because there has been an alarming shift in the proportion of children with a WHtR greater than 0.5, which should be a cause for concern, and attention should be paid to these children, as obesity-related morbidity is most likely to be present at this extreme in WHtR. A WHtR cutoff of 0.5 has been proposed as a simple means of indicating whether in adults, the amount of upper body fat accumulation is excessive and a risk to health. 
Table 3: Mean (SD) WHtR values of male and female adolescents in Ibadan, Nigeria

\begin{tabular}{llllll}
\hline Age (years) & Male & & Female & Difference \\
\hline & Mean & SD & Mean & SD & \\
$\mathbf{1 0}$ & 0.4247 & 0.03394 & 0.4433 & 0.06052 & 0.0186 \\
$\mathbf{1 1}$ & 0.4579 & 0.06888 & 0.4295 & 0.06696 & 0.0284 \\
$\mathbf{1 2}$ & $0.3910^{*}$ & 0.04040 & 0.4275 & 0.04202 & 0.0365 \\
$\mathbf{1 3}$ & 0.4077 & 0.02667 & 0.4195 & 0.3278 & 0.0118 \\
$\mathbf{1 4}$ & 0.4210 & 0.04446 & 0.4337 & 0.04320 & 0.0127 \\
$\mathbf{1 5}$ & $0.4139^{*}$ & 0.02964 & 0.4399 & 0.04065 & 0.026 \\
$\mathbf{1 6}$ & $0.4193^{*}$ & 0.03136 & 0.4687 & 0.04076 & 0.0494 \\
$\mathbf{1 7}$ & $0.4131^{*}$ & 0.03439 & 0.4687 & 0.04076 & 0.0556 \\
$\mathbf{1 8}$ & $0.4063^{*}$ & 0.02134 & 0.4420 & 0.1860 & 0.0357 \\
$\mathbf{1 9}$ & 0.4550 & 0.01432 & 0.4401 & 0.02561 & 0.0149 \\
\hline
\end{tabular}

$* \mathrm{P}<0.05$ vs girls

Furthermore, Pearson's Correlation Coefficient between height and waist circumference were 0.584 for male and 0.352 for female adolescents. Individual values for WHtR ranged between 0.31 and 0.59 in males; and 0.32 and 0.66 in females. Mean values of WHtR at yearly intervals are shown in Table 3. Mean WHtR ranged from 0.4247 in the 10 -year age group, to 0.4550 in the 19-year age group in males, and from 0.4433 to 0.4401 in girls of the same age groups respectively. Within the cohort, gender differences were consistent, with mean WHTR being higher in girls at all ages, except 11 and 19 , and reaching statistical significance except at ages 12, 15, 16, 17 and 18 years.

Table 4, shows the proportion of the whole cohort at yearly intervals that had a WHtR of 0.5 and above. A proportion of males aged 10,11, 14 and 16 had WHtR values above 0.5 while a proportion of females aged 10, 11, 12, 14, 15,16 and 17 had WHtR values above 0.5 .

Table 4: Percentage of adolescents in Ibadan, Nigeria with WHtR at 0.5 or above

\begin{tabular}{lllllll}
\hline Age (years) & \multicolumn{1}{c}{ Male } & \multicolumn{3}{c}{ Female } \\
\hline & $\mathbf{N}$ & $\mathbf{N}$ & $\mathbf{\%}$ & $\mathbf{N}$ & $\mathbf{n}$ & $\mathbf{\%}$ \\
$\mathbf{1 0}$ & 14 & 1 & 7.1 & 23 & 5 & 21.7 \\
$\mathbf{1 1}$ & 11 & 3 & 27.3 & 18 & 1 & 5.6 \\
$\mathbf{1 2}$ & 12 & 0 & 0 & 21 & 1 & 4.8 \\
$\mathbf{1 3}$ & 24 & 0 & 0 & 48 & 0 & 0 \\
$\mathbf{1 4}$ & 43 & 3 & 7.0 & 58 & 6 & 10.3 \\
$\mathbf{1 5}$ & 48 & 0 & 0 & 93 & 9 & 9.7 \\
$\mathbf{1 6}$ & 41 & 1 & 2.4 & 62 & 4 & 6.5 \\
$\mathbf{1 7}$ & 28 & 0 & 0 & 31 & 8 & 25.8 \\
$\mathbf{1 8}$ & 12 & 0 & 0 & 9 & 0 & 0 \\
$\mathbf{1 9}$ & 5 & 0 & 0 & 5 & 0 & 0 \\
\hline
\end{tabular}


The data presented above show that there is increase extra fat accumulation on the upper body. However, this finding agrees with other studies that have demonstrated that overweight and obesity in Nigerian children have increased recently (Ben-Bassey, Oduwole and Ogundipe, 2007; Akinpelu, Oyewole and Oritogun, 2008).

The body Mass Index (BMI) of the participants as shown in Table 5 reveals that female adolescents had significantly higher BMI than male through the age groups, though this difference was found to be significant at age groups $12-13,14-15$ and 16-17. This further explains the females were rather in the younger age groups, and had higher weight and shorter height which is an indication of higher BMI.

Table 5: BMI of Secondary School Adolescents in Ibadan North Local Government Area, Nigeria

\begin{tabular}{llll}
\hline & BMI & & \\
\hline Age & Male & Female & P \\
$\mathbf{1 0 - 1 1}$ & $17.8 \pm 3.4$ & $18.1 \pm 3.5$ & .725 \\
$\mathbf{1 2 - 1 3}$ & $16.6 \pm 2.1$ & $18.7 \pm 2.3$ & .000 \\
$\mathbf{1 4 - 1 5}$ & $17.5 \pm 1.8$ & $19.4 \pm 3.2$ & .000 \\
$\mathbf{1 6 - 1 7}$ & $18.7 \pm 1.9$ & $20.8 \pm 2.6$ & .000 \\
$\mathbf{1 8 - 1 9}$ & $20.0 \pm 2.2$ & $20.1 \pm 1.8$ & .921 \\
Total & $\mathbf{1 7 . 9} \pm \mathbf{2 . 3}$ & $\mathbf{1 9 . 5} \pm \mathbf{3 . 0}$ & $\mathbf{. 0 0 0}$ \\
\hline
\end{tabular}

\section{Percentage Body Fat (PBF)}

The Body Mass Index (BMI) is a simple index of obesity, estimated from weight and height. Epidemiological studies commonly use the BMI as an indicator of overweight and obesity. International classifications and definitions for overweight and obesity are based on BMI (WHO, 2000; Expert Panel on the identification, Evaluation and Treatment of Overweight in Adults, 1998), as weight and height can easily and accurately be measured. However, BMI does not directly measure body composition as it does not measure fat mass. The principle of BMI works on the assumption that at a given height, higher weight is associated with increased fatness (Benn, 1971). The widely used BMI alone is not sufficient for determining if an individual is obese, because it may not correspond to the same degree of fatness in different individuals (WHO, 2010).

The BMI gives particularly inaccurate information with regard to individuals with above-average lean muscle mass or body water, classifying such individuals as "overweight" or "obese" despite the fact that their body fat percentage would indicate they are in excellent physical condition. A good alternative to BMI is the direct determination of body fat mass or proportion. Body fat percentage or percentage body fat (PBF) is regarded as a better measure of obesity and an individual's fitness level, as it is a body 
measurement which directly calculates the particular individual's body composition. This section therefore focuses on the PBF of secondary students in Ibadan North, Nigeria, to further clarify the focus of the study.

Table 6: Percentage Body Fat (PBF) and Fat Mass (FM) of Adolescents by Age Group and Sex

\begin{tabular}{lllllll}
\hline \multicolumn{4}{c}{ PBF (\%) } & \multicolumn{3}{c}{ FM (kg) } \\
\hline Age & Male & Female & P & Male & Female & P \\
$\mathbf{1 0 - 1 1}$ & $11.5 \pm 7.0$ & $13.5 \pm 7.2$ & .294 & $4.7 \pm 3.8$ & $5.7 \pm 4.0$ & .309 \\
$\mathbf{1 2 - 1 3}$ & $8.1 \pm 5.9$ & $14.4 \pm 6.2$ & .000 & $3.4 \pm 2.6$ & $6.8 \pm 3.6$ & .000 \\
$\mathbf{1 4 - 1 5}$ & $9.7 \pm 5.0$ & $15.8 \pm 6.7$ & .000 & $4.3 \pm 2.4$ & $8.0 \pm 2.3$ & .000 \\
$\mathbf{1 6 - 1 7}$ & $5.8 \pm 4.0$ & $14.6 \pm 7.1$ & .000 & $3.4 \pm 2.7$ & $8.0 \pm 4.4$ & .000 \\
$\mathbf{1 8 - 1 9}$ & $7.6 \pm 6.6$ & $14.3 \pm 7.0$ & .012 & $4.5 \pm 4.0$ & $7.5 \pm 4.3$ & .055 \\
Total & $\mathbf{8 . 5} \pm \mathbf{5 . 6}$ & $\mathbf{1 4 . 9} \pm \mathbf{6 . 7}$ & $\mathbf{. 0 0 0}$ & $\mathbf{4 . 0} \pm \mathbf{2 . 9}$ & $\mathbf{7 . 5} \pm \mathbf{4 . 2}$ & $\mathbf{. 0 0 0}$ \\
\hline
\end{tabular}

The PBF (\%) and FM (Body Fat mass) (kg), as measured by the Bioelectric Impedance Analyser (BIA) are represented by table below. Overall mean PBF was $12.6 \pm 7.1 \%$ while overall mean FM was $6.3 \pm 4.2 \mathrm{~kg}$. Overall, the PBF was found to be significantly higher among female $(14.9 \pm 6.7 \%)$ than male $(8.5 \pm 5.6 \%)$ adolescents. Across age groups, the PBF was significantly higher in female among age groups 12-13, 14-15 and 16-17. Body Fat mass (FM) was also higher among female $(7.5 \pm 4.2 \mathrm{~kg})$ than male $(4.0 \pm 2.9 \mathrm{~kg})$ adolescents. Again, across age groups, this was significantly higher among age groups 1213, 14-15 and 16-17. The results from both the BMI and PBM of the study population further corroborate the socio-cultural context of central fatness given earlier in this discussion. The social expectations on fatness and attractiveness, and the changing dietary patterns among the Yoruba as stressed by Olutayo and Akanle (2009) with the increase of fattening foods in circulation has contributed significantly to the risk of overweight and obesity among adolescents in Nigeria.

\section{Conclusion and Recommendation}

Previous studies through the employment of BMI, have shown that there is increase in the central fatness of adolescents in Nigeria. This study also in the same vein corroborates the findings, that there is increasing central fatness among secondary school adolescents in Ibadan. This conclusion cannot be separated from the social and cultural values that describe expected wellness appearances within the symbolism of fatness. The increasing central fatness found by this study is partly related to celebrated fat body value system among the Yoruba, wrapped around the social expectation of having a fat child as a pseudo representation of class and status. Hence, it is as a matter of urgency that there should be a strong awareness on the dangers associated with increasing accumulation of excess fat among secondary adolescents in Ibadan. 


\section{References}

Adebanwi, W. (2010) Obafemi Awolowo and the making of Remo: the Local politics of Nigerian Nationalist by Insa Nolte. Journal of Modern African Studies, 48(3): 522-524.

Aderinto, S. (2015) When Sex Threatended the State: Illicit Sexuality, Nationalism and Politics in Colonial Nigeria, 1900-158. Urbana: University of Illinois Press.

Akinpelu, A.O., Oyewole, O.O. and Oritogun, K.S. (2008) Overweight and Obesity: Does It Occur in Nigerian Adolescents in an Urban Community? International Journal of Biomedical and Health Sciences, 4(1).

Akpa, M.R., Agomuoh, D.I., Alasia, D.D. (2006) Serum Lipid pattern of healthy adult Nigerians in Port Harcourt. Niger. J. Med., 15(2): 137-140.

Ali, M.M., Amialchuk, A. and Renna, F. (2011) Social Network and Weight Misperception among Adolescents. Southern Economic Journal, 77(4): 827-842.

Amodu, P.H., Mba, I.O., Lawson, L. (2005) Prevalence of Obesity and dyslipidemia in hypertensives in Abuja Nigeria. Scan. J. Clin. Lab. Inv. 240: 14-17.

Auld, M.C. and Powell, M. (2009) Economics of Food Energy Density and Adolescent Body weight. Economica. New Series, 76(304): 719-740.

Barbas, S. (2004) Weighty Issues. American Quqrterly, 56(4): 1115-1124.

Ben-Bassey, U.P., Oduwole, A.O. and Ogundipe, O.O. (2007) Prevalence of overweight and obesity in Eti-Osa LGA, Lagos, Nigeria. Obes Rev, 8(6): 475-479.

Bolarinwa, T.A. (1987) Girls and science Education in Nigeria. Journal of Negro Education, 56(4): 580-587.

Brad, L. Weiss (2004) Review of Rebecca Popenoes Feeding Desire: Fatness and Beauty in the Sahara. Journal of Anthropological Research, London and New York: Routledge (2003). 60(4): 589-590.

Brewis, A.A. (2010) Big-Body Symbolism, Meaning and Norms. In Obesity: Cultural and Biocutural Perspectives. US: Rutgers University Press.

Buffa, R., Floris, G., Marini, E. and Ortu, A. (2003) Size and shape modifications in Sardinian Adolescent Girls. Anthropologischer Anzeiger, 61(4): 421-434.

Chen, R. and Tunstal-Pedoe, H. (2005) Socioeconomic Deprivation and Waist Circumference in Men and Women: The Scottish MONICA surveys 19891995. European Journal of Epidemiology, 20(2): 141-147.

Copper, R., Rotimi, C., Ataman G. et al. (1997) The prevalence of hypertension in seven populations of West African origin. Am. J. pub. Health. 87: 160-168.

Dworkin, S.L. and Wachs, F.L. (2009) Body Panic: Gender, Health and the Selling of Fitness. New York: New York University Press. 
Fan, J., Dai, W. and Wu, J. (2005) Visual Perception of Male Body attractiveness. Proceeding: Biological Science, 272(1560): 219-226.

Gage-Brandon, Anastasia J. (1992) The Polygyny-Divorce relationship: A case study of Nigeria. Journal of marriage and family, 54(2): 285-292.

Han, T.S., Van Leer E.M, Seidell, J.C. and M.E.J. Lean (1995) Waist Circumference Action Levels in The Identification of Cardiovascular Risk Factors: Prevalence Study In A Random Sample. BMJ: British Medical Journal, 311(7017): 1401-1405.

Ho, M.Y., Cheung, F.M. and Cheung, S.F. (2008) Personality and Life Events as Predictors of Adolescents' Life Satisfaction: Do life events mediate the link between personality and life satisfaction? Social Indicators Research 89(3): 457-471.

Icks, A., Moebus, S., Feuersenger, A., Haastert, B., Jockel, K. and Mielck, A. (2007) Widening of social gradient in obesity risk? German national health surveys 1990 and 1998. European Journal of Epidemiology, 22(10): 685690.

Johnson, T.O. (1970) Prevalence of overweight and obesity among adult subjects of an urban African population. Br. J. of preventive and Social Med. 24: 105-109.

Kadiri, S. and Salako, B.L. (1997) Cardiovascular Risk Factors in Middle Aged Nigerians. East African Medical Journal, 74: 303-307.

Kazeem, A., Jensen, L. and Stokes, C.S. (2010) School attendance in Nigeria: Understanding the impact and intersection of Gender, Urban-Rural Residence and Socioeconomic status. Comparative Education Review, 54(2): 295-319.

Kazeem, A., Jensen, L. and Stokes, C.S. (2010) School attendance in Nigeria: Understanding the impact and intersection of Gender, Urban-Rural Residence and Socioeconomic status. Comparative Education Review, 54(2): 295-319.

Kirk, J. and Garrow, S. (2003) Girls in Policy: challenges for the education Sector. Agenda: Empowering Women for Gender Equity, 56: 4-15.

Lawoyin, T.O., Asuzu, M.C. and Karfman, J. (2002) Prevalence of cardiovascular risk factors in an African urban inner city community. West Afr. J. Med., 21(3): 208-211.

Lincove, J.A. (2008) Growth, Girls' Education and Female Labor: A Longitudinal Analysis. Journal of Developing Areas, 41(2): 45-68.

McCarthy, H.D. and Ashwell, M. (2006) A study A study of central fatness using waist-to-height ratios in UK children and adolescents over two decades supports the simple message- 'keep your waist circumference to less than half your height'. International Journal of Obesity, $\quad 30: \quad 988-$ 992.

McCarthy, H.D., Ellis, S.M. and Cole, T.J. (2003) Central Overweight and Obesity in British youth aged 11-16 years: cross sectional surveys of waist circumference. BMJ: British Medical Journal, 326(7390): 624-626. 
Meagher K. (2006): Social Capital, Social Liabilities and Political capital: Social Networks and Informal Manufacturing in Nigeria. African Affairs 105(421): 553-582

Moffat, T. (2010) The "Childhood Obesity Epidemic": Health crisis or Social construction. Medical Anthropology Quarterly, 24(10: 1-21.

Nolte, I. (2004) Identity and Violence: The Politics of Youth in Ijebu-Remo, Nigeria. Journal of Modern African Studies, 42(1): 61-89.

Nolte, I. (2009) Obafemi Awolowo and the Making of Remo: The Local Politics of a Nigerian Nationalist. UK: Edinburgh University Press.

Ogunjuyigbe, P.O., Ojoteitimiu, E.O. and Akinlo, A. (2006) Science Education in Nigeria: An examination of Peoples' Perceptions about Female participation in Science, Mathematics and Technology. Journal of Science Education and Technology, 15(3/4): 277-284.

Okoh, Osabohien M. and Okoh, Mathew (2013) Socio-Demographic Correlates of Overweight and Obesity among Women of Reproductive Age in Nigeria. African Journal of Reproductive Health/La Revue Africaine de la Santé Reproductive, 17(4): 66-76.

Olutayo, A.O. and Akanle, O. (2009) Fast food in Ibadan: an Emerging Consumption Pattern. Africa: Journal of the International African Institute, 79(2): 207-227.

Oni, B. (1991) Contemporary Courtship and Marriage practices among the Yoruba. International Journal of Sociology of Family, 21(2): 145-160.

Ostojic, S.M., Stojanovic, M.D., Stojanovic, V., Maric, J. and Njaradi, N. (2011) Correlation between Fitness and Fatness in 6-14-year Old Serbian school Children. Journal of Health, Population and Nutrition, 29(1): 5360.

Pestieau, P. and Ponthiere, G. (2013) Childbearing age, Family allowances and Social security. Southern Economic Journal, 80(2): 385-413.

Popenoe, R. (2003) Feeding Desire: Fatness, Beauty and Sexuality among a Saharan People. US: Rutledge.

Quelly, S.B. and Lieberman, L.S. (2011) Global prevalence of overweight and obesity in preschoolers. Anthropologischer Anzeiger, 68(4): 437-456.

Riddell, J.B. (1992) Things fall Apart Again: Structural Adjustment Programmes in Sub-Saharan Africa. The Journal of Modern African Studies, 30(1): 53-68.

Rosenblum, G.D., Lewis, M. (1999) The Relations among Body Image, Physical Attractiveness and Body Mass in Adolescence. Child Development, 70(1): 50-64.

Rothbart, M.K. (2007) Temperament, Development and personality. Current Directions in Psychological Science, 6(4): 207-212.

Schonfeld, W. (1984) African Art from Nigeria and the Ivory Coast. African Arts, 17(2): 78-79. 
Smith, H.A. (2007) Teaching Adolescents Educational Psychology as a science of Signs. USA: University of Toronto Press.

Sudha, P.P., Paul, A.S. and Diane, B.M. (2013) Conceptual heuristic models of the interrelationships between obesity and the occupational environment. Scandinavian Journal of Work, Environment and Health, 39(3): 221-232.

Tibenderana, P.K. (1985) the Beginnings of Girls' Education in the Native Administration of schools in Northern Nigeria, 1930-1945. The Journal of African History, 26(1): 93-109.

Upton, R.L. (2001) 'Infertility makes you Invisible': Gender, Health and the Negotiation of Fertility in Northern Bostwana. Journal of Southern African Studies, 27(2): 349-362.

Walker, E.A. (2000) Happy days are here again: Cocoa Farmers, middlemen traders and Structural Adjustment Program in Southwestern Nigeria, 1986-1990s. Africa Today, 47(2): 151-169.

Wedwick, L. (1998) The last Accepted Prejudice: Fat characters in Children's series Fiction. Studies in Popular Culture, 20(3): 19-31.

Wiederman, M.W., Hurst, S.R. (1998) Body Size, Physical attractiveness, and Body Image among young Adult Women: Relationships to Sexual Experience and Sexual Esteem. The Journal of Sex Research, 35(3): 272281.

World Health Organization (WHO) (2010) Obesity and overweight, World Health Organization: http://www.who.int/dietphysicalactivity/publications/ facts/obesity/en/ Retrieved 26th March, 2010.

World Health Organization (WHO) (2012) 10 facts on obesity. Retrieved 30th March, 2012.

Yiting, W., Eric, J., Jacobs, A.V., Patel, C.R., Marjorie, L.M., Michael, J.T. and Eugenia, E.C. (2008) A Prospective Study of Waist Circumference and Body Mass Index in Relation to Colorectal Cancer Incidence. Cancer Causes \& Control, 19(7): 783-792. 